\title{
Experimental study of water evaporation rate, at the surface of aqueous solution, under the effect of a discontinuity of chemical potential - effect of water activity and air pressure
}

\author{
J.-C. Bénet ${ }^{1}$, S. Ouoba ${ }^{2}$, F. Ouedraogo ${ }^{3}$, F. Cherblanc ${ }^{1}$
}

Corresponding author: fabien.cherblanc@umontpellier.fr

${ }^{1}$ LMGC, Université de Montpellier, CNRS, Montpellier, France

${ }^{2}$ LPCE, Université Joseph Ki-Zerbo, Ouagadougou, Burkina-Faso

${ }^{3}$ GERME \& TI, Université Nazi Boni, Bobo Dioulasso, Burkina Faso.

\begin{abstract}
The aim of this communication is to analyse the influence of water activity and total pressure on water evaporation. The system is composed of liquid and gas phases, separated by a plane surface, contained in a cylinder whose volume is regulated by a piston. Water activity is regulated by saturated salt solutions and pressure by the piston. The experimental device and procedures were defined to limit the temperature variation at the interface. A transient method is used. From a steady state, a volume increment is imposed; the resulting non-equilibrium leads to an increase in the partial pressure of water vapour to the equilibrium pressure imposed by the solution. Numerical calculation shows little variation in temperature in the gas-liquid interface under the experimental conditions. An evaporation model is adopted taking into account chemical potential discontinuity at the interface. The surface flux evaporation and chemical potential jump at the interface are deducted from the total pressure recording. In the neighbourhood of equilibrium, the surface flux of phase change is shown to be proportional to the chemical potential jump. The surface coefficient of evaporation increases with the total pressure of the gas phase and water activity.
\end{abstract}

Key words: surface evaporation rate; chemical potential; water activity; gas pressure; transient method. 


\section{Nomenclature}

$a_{w} \quad$ : Activity of water (/)

$C_{\alpha} \quad$ : Specific heat capacity of the phases; $\alpha=g$ for the gas phase, $\alpha=l$ for the liquid phase $\left(\mathrm{J} \mathrm{kg}^{-1} \cdot \mathrm{K}^{-1}\right)$

$D_{v} \quad$ : Diffusion coefficient of water vapour in air $\left(\mathrm{m}^{2} \cdot \mathrm{s}^{-1}\right)$

$h_{g} \quad:$ Thickness of the gas phase (m)

$h_{l} \quad:$ Thickness of the liquid phase $(\mathrm{m})$

$J_{v} \quad$ : Evaporation flux by surface unit and unit time $\left(\mathrm{kg} \cdot \mathrm{m}^{-2} \cdot \mathrm{s}^{-1}\right)$

$J_{d i} \quad$ : Diffusive flux of the vapour $(\mathrm{i}=\mathrm{v})$ and air $(\mathrm{i}=\mathrm{a})\left(\mathrm{kg} \cdot \mathrm{m}^{-2} \cdot \mathrm{s}^{-1}\right)$

$L^{S} \quad$ : Isothermal phase change coefficient by unit surface (kg.K.s.m $\left.{ }^{-4}\right)$

$M \quad$ : Molar mass of water $\left(0.018 \mathrm{~kg} \cdot \mathrm{mol}^{-1}\right)$

$p_{g} \quad:$ Pressure of the gas phase $(\mathrm{Pa})$

$p_{i} \quad$ : Partial pressure of air, (i=a) and vapour $(\mathrm{i}=\mathrm{v})(\mathrm{Pa})$

$p_{v}^{e q}:$ Partial pressure of water vapour at the equilibrium with water in a solution $(\mathrm{Pa})$.

$p_{v s}(T):$ Saturated vapour pressure at temperature $(\mathrm{T})$

$p^{+} \quad:$ Reference pressure $(\mathrm{Pa})$

$p_{0} \quad:$ Standard pressure $(101325 \mathrm{~Pa})$

$Q \quad$ : Energy flux $\left(\mathrm{J} \cdot \mathrm{m}^{-2} \cdot \mathrm{s}^{-1}\right)$

$R \quad$ : Perfect gas constant $\left(8.314 \mathrm{~J} . \mathrm{K}^{-1} \mathrm{~mol}^{-1}\right)$

$T \quad$ : Temperature (K)

$T_{l} \quad$ : Temperature of the liquid phase (K)

$T_{v} \quad:$ Temperature of water vapour $(\mathrm{K})$

$T_{0} \quad$ : Standard temperature $(273.15 \mathrm{~K})$

$v_{\alpha}^{k} \quad:$ Gas phase velocity $(\alpha=g)$, of air $(\alpha=a)$ and water vapour $(\alpha=v)\left(\mathrm{m} \cdot \mathrm{s}^{-1}\right)$

$z \quad$ : Elevation from the liquid-gas interface (m) 


\section{Greek symbols}

$\lambda_{\alpha} \quad$ : Thermal conductivity of the phases; $(\alpha=g)$ for the gas phase, $(\alpha=l)$ for the liquid phase $\left(\mathrm{W} \cdot \mathrm{m}^{-1} \cdot \mathrm{K}^{-1}\right)$

$\mu_{v} \quad$ : Mass chemical potential of water vapour $\left(\mathrm{J}_{\mathrm{kg}} \mathrm{kg}^{-1}\right)$

$\mu_{w} \quad$ : Mass chemical potential of liquid water $\left(\mathrm{J} \cdot \mathrm{kg}^{-1}\right)$

$\mu^{+} \quad$ : Reference mass chemical potential reference, function of the temperature $T$, at reference pressure $P^{+}\left(\mathrm{J}_{\mathrm{kg}}{ }^{-1}\right)$

$\rho_{\alpha} \quad$ : Mass density of gas phase $(\alpha=g)$ of air $(\alpha=a)$ and water vapour $(\alpha=v)\left(\mathrm{kg} \cdot \mathrm{m}^{-3}\right)$

$\varepsilon \quad$ : Correcting coefficient for evaporation rate (/)

\section{Introduction}

Liquid-gas phase change is involved in many mass and energy transfer. Examples include evaporation over large bodies of water (lakes and seas) and their impact on climate, evaporation from the soil surface associated with desertification, industrial distillation and refining processes, high temperature geothermal processes, drying of food and industrial products.

Surface evaporation involves mass and energy transfer phenomena related to:

(i) temperature discontinuity at the interface and its variations on both sides of the interface,

(ii) convective and diffusive transport in both phases,

(iii) chemical potential discontinuity at the interface, generally associated with a difference between the vapour partial pressure and the equilibrium vapour pressure of liquid water.

The simultaneous consideration of all these mechanisms and their coupling makes theoretical and experimental analysis difficult. Concerning phenomena (i) and (ii), Fang and Ward [1] performed a phase change experiment for a spherical interface separating pure water and water vapour. Partial pressure was kept constant at values between 194.7 and $596 \mathrm{~Pa}$ by a flux of vapour. The tests were carried out for temperatures of 15,26 and $35^{\circ} \mathrm{C}$. The average surface evaporation flux varied between $70 \mu \mathrm{l} / \mathrm{h}$ and $160 \mu \mathrm{l} / \mathrm{h}$. The temperature was measured in the fluid and gas phases by thermocouples. The measurements showed an interfacial temperature discontinuity up to $8^{\circ} \mathrm{C}$ for evaporation rates of $160 \mu \mathrm{l} / \mathrm{h}$. The temperature on the vapour side was greater than the temperature on the liquid side.

Concerning phenomena (i) and (ii), Gatapova et al. [2] brought heat locally to a thin layer of water at atmospheric pressure. Temperature and heat flux are recorded during experiments. Various thermocouples ( $4 \mu \mathrm{m}$ diameter) allow measuring the temperature jump at the waterair interface. A temperature jump of about $0.2^{\circ} \mathrm{C}$ is detected for the liquid surface temperature of $35.2^{\circ} \mathrm{C}$ and the heater temperature of $43.6^{\circ} \mathrm{C}$. They conclude that the value of temperature jump depends not only on evaporation intensity but also on the temperature gradients in liquid and gas phases near the interface. 
Kazemi et al. [3] conducted an experimental and theoretical study on the non-stationary evaporation of water at low pressure. They proposed a mathematical model of the system which takes into account mass, momentum and heat transport in liquid and gas phases, as well as the phase change at the interface. The study allowed the description of the mass transfer through the interface. The experiments consisted in measuring the velocity field in the central plane of the evaporating water. In addition, the temperature distribution at the liquid-vapour interface was measured with a fine thermocouple. The results showed good correlation between simulation and experiment. So, this model was used to reveal certain behaviours on the phenomenon of evaporation difficult to access by experiments alone.

In the experiments proposed by Badam et al. [4], concerning phenomena (i), a cylindrical water vapour interface is subjected to heat input. Heaters provided energy to the interface. A moving thermocouple was used to measure the temperature profile in the liquid and vapour phases. The water flow at the interface was determined from the quantity of water injected into the liquid phase. These measurements were used to deduce the flow of evaporated water and the temperature discontinuity at the interface, as well as heat flows in the liquid and gas phases near the interface. Temperature discontinuity depended on the imposed energy; it was about $2^{\circ} \mathrm{C}$ without input of heat energy, and reached values up to $10^{\circ} \mathrm{C}$ when the temperature was regulated at $80^{\circ} \mathrm{C}$. These values are approximately 10 to 20 times higher than those given by the kinetic theory of gases [4].

The experiments mentioned that the addition or removal of mass or heat at the interface increases phase change. The release of latent heat of cools the two phases and leads to temperature discontinuity at the interface. These experiments are performed in steady state, the temperature jump is determined at the end of the experiment, which supposes that the interface has reached an equilibrium, which is far from immediate.

In the environment, solvent, usually water, is generally impure. When the water contains salts or other chemical compounds in solution, the activity of the water is modified as well as the evaporation rate. Limited to aqueous saline saturated solutions, the objective of the experimental study proposed here is to validate a macroscopic evaporation law triggered by a chemical potential at the interface (phenomenon (iii) $[4,5,6]$. The influence of aqueous water activity and total gas pressure on the evaporation rate will be analysed in this contribution.

\section{Experimental studies of gas-liquid evaporation with low temperature variation}

The choice of a jump in chemical potential as the cause of evaporation requires carrying out an experiment that minimizes the magnitude of mechanisms (i) and (ii); this is achieved if the experiment is carried out in a closed environment in the absence of diffusion and if the temperature variation at the interface is very low. However, the imposed conditions must be able to create an interfacial discontinuity of the chemical potential. To avoid a prevailing temperature jump at the interface and to restrict the movement of fluids, the experiments are carried out under transient conditions. In a close cylinder containing liquid and vapour water, the phase change will be triggered by a rapid supply of mechanical energy. This energy will be provided by an increment of volume occupied by the gaseous phase, causing the vaporization of a small quantity of water. Physical quantities will be recorded during the return to 
equilibrium in order to analyse the phase change resulting from a discontinuity of the chemical potential. However, this experimental procedure can still induce evaporation under the action of mechanisms (i) and (ii), requiring to discuss the assumptions made.

\section{Description of the experimental device}

The experimental device, presented in Fig.1, was recently developed to characterize the liquidgas equilibrium in hygroscopic porous materials [7]. The same apparatus is used here to analyse the kinetics between two equilibrium situations.

Water activity is controlled by means of standard saturated salt solutions (Tab.2). The solution under investigation was placed in a cylindrical tank (a), it thickness being of the order of $5 \mathrm{~mm}$. A piston pump (c) was placed above the solution in order to apply gas pressure in (g) below the atmospheric pressure. The piston chamber volume is modified by a screw system (d) with a graduated ruler (e). O-ring gaskets (f) ensured perfect air tightness so that the system could be considered closed.

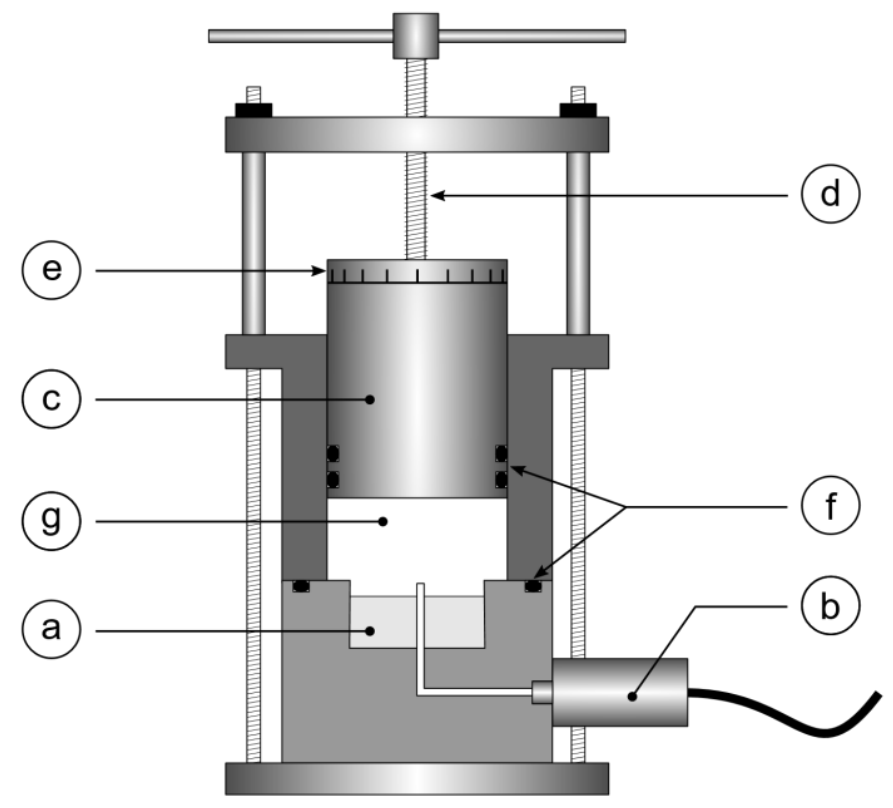

Figure 1: Schema of the experimental device

Table 1: Dimensional characteristics of the experimental device

\begin{tabular}{ll}
\hline Solution height & $15 \mathrm{~mm}$ \\
\hline Piston diameter & $44.5 \mathrm{~mm}$ \\
\hline Piston displacement for one rotation & $1.75 \mathrm{~mm}$ \\
\hline Volume increment for one rotation & $2.722 \mathrm{~cm}^{3}$
\end{tabular}


Some characteristic dimensions are given Tab.1. A pressure transducer (b) (Druck, PMP4030AB) was used to record the total pressure of the gas phase, $p_{g}$, throughout the process with accuracy of $\pm 10 \mathrm{~Pa}$. The whole device was placed in a thermo-regulated bath at $30^{\circ} \mathrm{C}$ to ensure a constant temperature at the outer surface of the cylinder. As the device was made of stainless steel its high thermal inertia led to low temperature variations. Data acquisition was performed through a National Instrument DAQ card and analysed using LabView software.

\section{Operating mode}

The tests were carried out for total pressures of 55,75 and $95 \mathrm{kPa}$. In order to regulate both the total pressure of the gas phase and the partial pressure of water vapour, the following procedure was adopted.

1/ To adjust the final total pressure, preliminary experiments were carried out. The solutions were introduced and the piston was placed in the low position. By using the pressure sensor, the total pressure was brought to the desired value. The device was then disassembled and the height of the cavity (g), noted $h_{g}$ was measured. The gaseous phase being composed of $96 \%$ of air, in the most unfavourable case of pure water, $h_{g}$ depended little on the composition of the solution. For the three pressures $(55,75$ and $95 \mathrm{kPa})$, the average values of $h_{g}$ were respectively: 14.22, 24.09 and $26.24 \mathrm{~mm}$.

2/ As can be seen in Tab.2 the minimum equilibrium partial pressure was $500 \mathrm{~Pa}$ for $\mathrm{LiCl}$. It was decided to impose a partial pressure variation of $500 \mathrm{~Pa}$ with respect to the equilibrium pressure, for all salts. To regulate the pressure, the piston was placed in $h_{g}^{0}$ and brought very quickly to position $h_{g}$ so that evaporation did not have time to develop. The law of perfect gases applied to the vapour between $h_{g}^{0}$ and $h_{g}$ gives:

$$
p_{v}^{e q} \times h_{g}^{0}=\left(p_{v}^{e q}-500\right) h_{g}
$$

This relation made it possible to calculate $h_{g}^{0}$ which takes the average values of $12.42 \mathrm{~mm}$ for $55 \mathrm{kPa}, 20.87 \mathrm{~mm}$ for $75 \mathrm{kPa}$ and $22.37 \mathrm{~mm}$ for $95 \mathrm{kPa}$. The couple $\left(h_{g}^{0}, h_{g}\right)$ set the initial value of the vapour partial pressure to $500 \mathrm{~Pa}$ and the total pressure to the desired pressure.

3/ With the device open, the piston was placed in position $h_{g}^{0}$. After closing, the device was immersed in a bath thermo-regulated at $30^{\circ} \mathrm{C}$ for 30 minutes. When equilibrium was reached, the partial pressure of the vapour stabilized at the equilibrium partial pressure fixed by the solution. The piston was moved up by the screw system. The value of the total pressure was monitored precisely by means of the pressure transducer in order to reach the desired total pressure. Raising the piston induced the expansion of the gas phase in the cavity (g) and therefore decreased the partial pressure of the water vapour.

4/ The phase change took place in a closed space ( $\mathrm{g}$ ) of fixed volume. The total pressure was recorded until a new equilibrium was obtained. 
5/ At the final equilibrium, the device was disassembled and the value of $h_{g}$ was measured (Tab.3). This value differed little from the expected value, but it was more precise and was adopted during exploitation of the experiments. The thickness of the solution was measured at the beginning and at the end of the experiment; there was no variation in the position of the surface during the experiment.

\section{Presentation of the raw results}

The typical changes in gas pressure during return to equilibrium are given in Fig. 2 for the various salt solutions. This figure concerns a temperature of $30^{\circ} \mathrm{C}$ and total gas pressure in the order of $95 \mathrm{kPa}$. Similar evolutions were recorded for $p_{g}=75 \mathrm{kPa}$ and $55 \mathrm{kPa}$. At the end of the experiment, the total pressure stabilized at $p_{g}(t=\infty)$, the vapour pressure was equal to its equilibrium vapour pressure, $p_{v}^{e q}$ fixed by the solution. This allowed the partial air pressure $p_{a}(t=\infty)$ to be determined.

$$
p_{a}(t=\infty)=p_{g}(t=\infty)-p_{v}^{e q}
$$

Table 2: Water activity for various saturated salt solutions at $30^{\circ} \mathrm{C}$

\begin{tabular}{lcc}
\hline Salt & $\begin{array}{c}\text { Water activity } \\
(/)\end{array}$ & $\begin{array}{c}\text { Equilibrium vapour pressure } \\
(\mathbf{P a})\end{array}$ \\
\hline Lithium chloride $\mathrm{LiCl}$ & $0.12 \pm 0.002$ & 504 \\
\hline Magnesium chloride $\mathrm{MgN} 2 \mathrm{O} 6$ & $0.23 \pm 0.001$ & 966 \\
\hline Potassium acetate $\mathrm{KCH} 3 \mathrm{CO} 2$ & $0.55 \pm 0.001$ & 2310 \\
\hline Sodium nitrite $\mathrm{NaNO} 2$ & $0.66 \pm 0.001$ & 2772 \\
\hline Sodium chloride $\mathrm{NaCl}$ & $0.751 \pm 0.001$ & 3154 \\
\hline Potassium chloride $\mathrm{KCl}$ & $0.85 \pm 0.004$ & 3570 \\
\hline Potassium sulfate $\mathrm{K} 2 \mathrm{SO} 4$ & $0.970 \pm 0.004$ & 4074 \\
\hline Pure water & 1.0 & 4200 \\
\hline
\end{tabular}




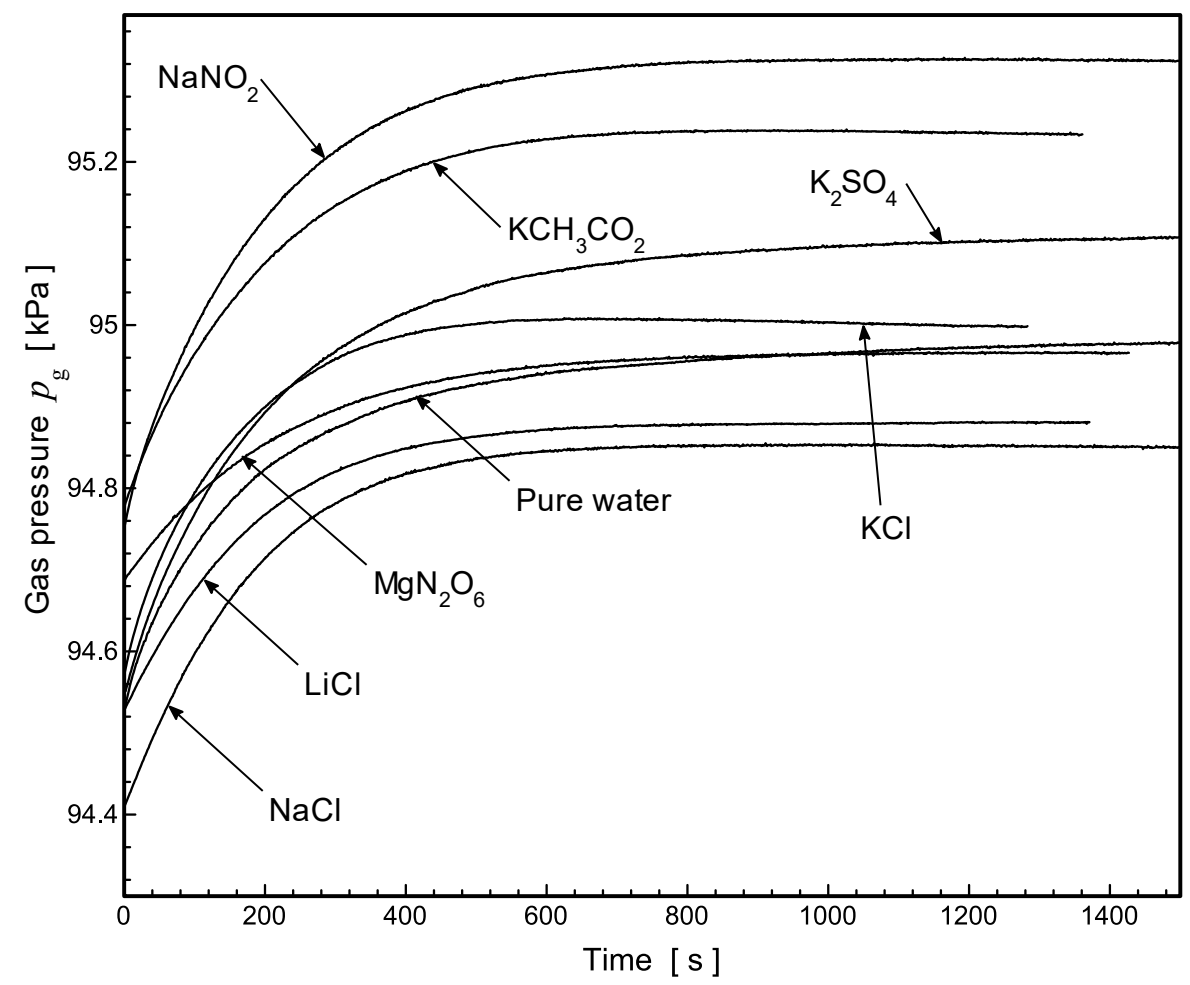

Figure 2: Evolution of the gas pressure pg as a function of time measured with different saturated salt solutions $(\mathrm{pg} \approx 95 \mathrm{kPa})$

The average value of the pressure difference between the initial time and the end of the experiment was (Tab.2): $420 \mathrm{~Pa}$ at $95 \mathrm{kPa}, 462 \mathrm{~Pa}$ at $75 \mathrm{kPa}$ and $490 \mathrm{~Pa}$ at $55 \mathrm{kPa}$, while the predicted value was $500 \mathrm{~Pa}$. Beyond the fluctuations of the experimental conditions, the observed increase seems to show that the hypothesis of no vaporization when the piston goes from $h_{g}^{0}$ to $h_{g}$ is not entirely satisfied and that the higher the total pressure, the faster the speed.

\section{Assumptions}

Parasitic phenomena may occur during the return to equilibrium; it should be checked that their order of magnitude remains low. Verification then focuses on five hypotheses:

H1- variation of the thickness of the liquid layer of water,

H2- temperature jump at the interface,

H3- vapour diffusion flux at the interface,

H4- temperature evolution of the liquid phase,

H5- vapour diffusion above solution.

\section{H1- Variation of the thickness of the liquid slide}

The value of the variation in partial pressure of the vapour is in order of $400 \mathrm{~Pa}$ for pure water (Fig.2), with a thickness $h_{g}$ of $30 \mathrm{~mm}$ and a piston area of $0.15 \times 10^{-2} \mathrm{~m}^{2}$, the perfect gas law gives an evaporated water mass of $0.13 \times 10^{-6} \mathrm{~kg}$ and therefore a variation of the thickness of the liquid phase of $0.86 \times 10^{-4} \mathrm{~mm}$. The hypothesis $\mathrm{H} 1$ of a stationary liquid - gas interface can be adopted. 


\section{H2- Temperature jump at the interface}

With a latent heat of $2400 \mathrm{~kJ}^{\mathrm{kg}}{ }^{-1}$, the heat necessary to evaporate the water mass is $0.156 \mathrm{~J}$. It is assumed that this heat is entirely taken from the liquid phase of thickness $5 \mathrm{~mm}$ and mass of $0.75 \times 10^{-2} \mathrm{~kg}$. With a specific heat of $4200 \mathrm{~J} \cdot \mathrm{kg}^{-1} \mathrm{~K}^{-1}$, the variation of the average temperature of the solution is $-0.005 \mathrm{~K}$. This temperature drop is due to evaporation; the conduction in the metal walls and the radiation of the metal surfaces reduce the variation in temperature. The phenomena of convection in liquid and gaseous phases have the effect of homogenizing the temperature. The value calculated above is an upper limit of the fall in average temperature.

\section{H3- Vapour diffusion flux at the interface}

The total surface flux of material at the following interface $z$ is the sum of the surface flux of phase change of water and the surface flux of gases dissolved in water. In the case of nitrogen (partial pressure $78 \mathrm{kPa}$ ), in equilibrium with dissolved nitrogen, with a Henry coefficient of $8.5 \times 10^{9} \mathrm{~Pa} \cdot \mathrm{m}^{3} \cdot \mathrm{mol}^{-1}$, the mass of nitrogen dissolved in water in the initial state is $8.82 \times 10^{-8} \mathrm{~kg}$, before the experiments. In the unfavourable hypothesis that this mass of air would be found in gaseous form in part (g) of the device at the end, the perfect gas law would give a pressure variation of $0.8 \times 10^{-2} \mathrm{~Pa}$. This is negligible in comparison with measured pressure variations (Fig.2). The same order of magnitude is obtained with the oxygen of the air. This calculation shows that the pressure variations of Fig. 2 are entirely due to the evaporation of the water. With the law of perfect gases applied to the mass of gas contained in $(\mathrm{g})$, the vapour flux is given by:

$$
J_{v}=\frac{M}{R T} h_{g} \frac{d}{d t} p_{g}
$$

\section{H4- Temperature evolution at the liquid surface}

With the vapour flow (3) it is possible to refine the temperature calculation at the interface given in $\S 3$. The heat equation has been solved in the liquid phase of $5 \mathrm{~mm}$ tick, in the absence of convection movements. The thermal conductivity is taken to be $0.65 \mathrm{~W} \cdot \mathrm{m}^{-1} \mathrm{~K}^{-1}$. The initial temperature of the liquid phase is $30^{\circ} \mathrm{C}$. At the base of the liquid phase the temperature is assumed constant and equal to $30^{\circ} \mathrm{C}$. At the surface, the heat flow is imposed equal to the latent heat of vaporization of water multiplied by the vapour flow (3), the derivative of the total pressure being deduced from Fig.2. Based on numerical computation, Fig.3 shows the evolutions of the average temperature of liquid phase and of the temperature at the surface of the liquid phase. The maximum temperature variation at the interface is $-0.007 \mathrm{~K}$. The variation of the average temperature of the liquid phase is $-0.002 \mathrm{~K}$. These values confirm the small variations determined by the approximate calculation $(-0.005 \mathrm{~K})$ and help to justify hypothesis $\mathrm{H} 4$ of a small temperature variation at the interface.

Table 3: Characteristic values of experiments

\begin{tabular}{lccc}
\hline Total reference pressure $(\mathrm{kPa})$ & 55 & 75 & 95 \\
\hline Value of $h_{g}{ }^{0}(\mathrm{~mm})$ & $22.37 \pm 0.05$ & $20.87 \pm 0.05$ & $12.42 \pm 0.05$ \\
\hline $\begin{array}{l}\text { Mean value of } h_{g} \text { measured at the end of the } \\
\text { experiment }(\mathrm{mm})\end{array}$ & $26.24 \pm 0.05$ & $24.10 \pm 0.05$ & $14.21 \pm 0.05$ \\
\hline
\end{tabular}




\begin{tabular}{llll}
\hline $\begin{array}{l}\text { Mean value of the variation of gas pressure (Fig 2) } \\
(\mathrm{Pa})\end{array}$ & $420 \pm 10$ & $462 \pm 10$ & $490 \pm 10$ \\
\hline
\end{tabular}

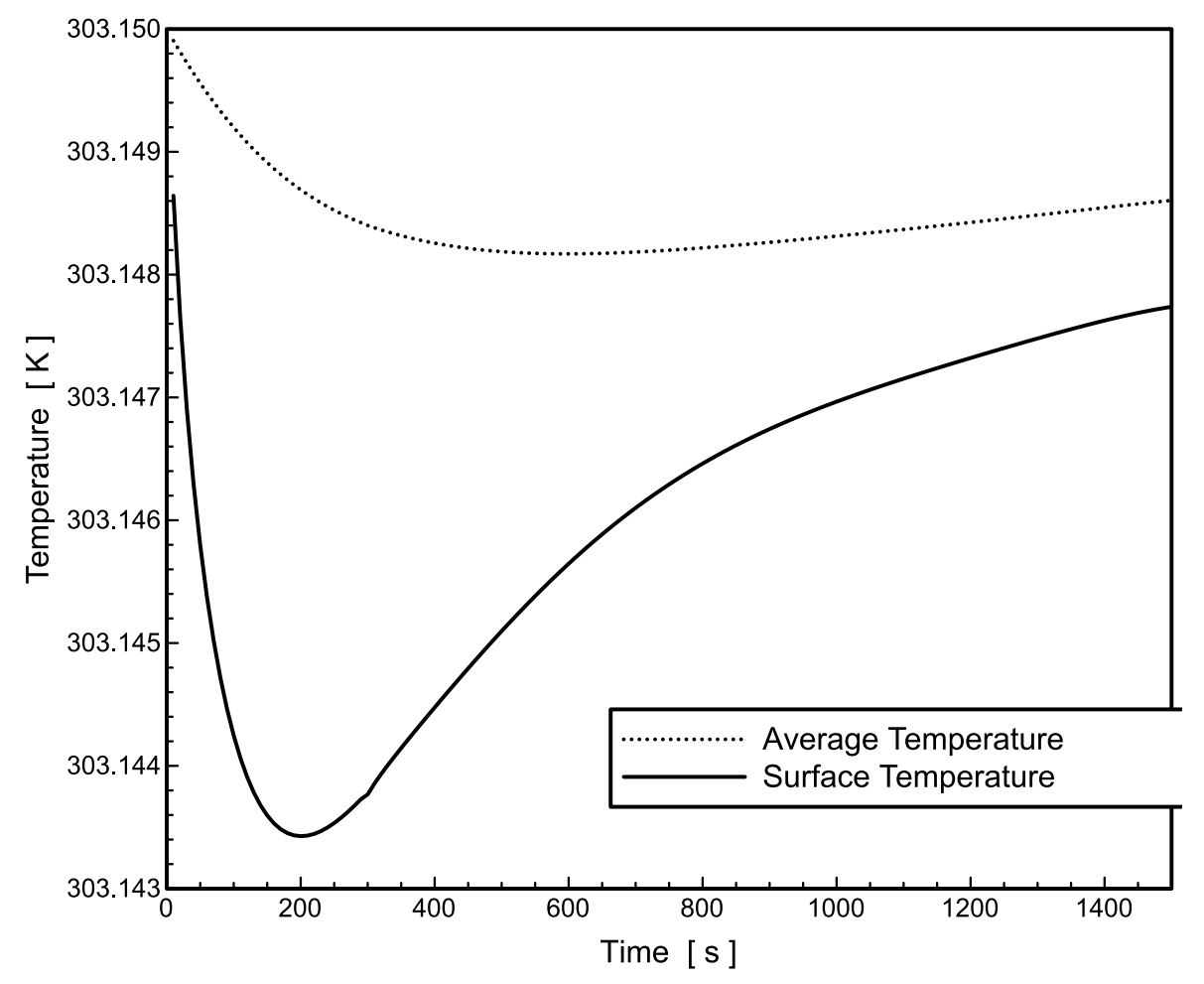

Figure 3: Evolution of the average and surface temperature of the liquid phase from numerical computation - Case of pure water

It remains to be verified that the phase change is not managed by a thermal equilibrium at the surface. Between $28^{\circ} \mathrm{C}$ and $32^{\circ} \mathrm{C}$, for pure water, the variation of saturating pressure variation can be approximated by a line

$$
\Delta p_{v}^{e q}=232.81 \times \Delta T
$$

With $\Delta T=-0.007^{\circ} \mathrm{C}$, this relation gives a variation of the surface pressure of $1.7 \mathrm{~Pa}$, which represents only a small part of the variation of partial pressure, this being of the order of $400 \mathrm{~Pa}$.

\section{H5- Vapour diffusion above the solution}

In order to evaluate the impact of diffusion on the phase change, the partial pressure profile of the vapour in the cavity (g) (Fig.1) can be determined. With hypothesis H4, using the ideal gas law, the vapour transfer in the gas phase is described by a classical diffusion equation:

$$
\frac{\partial p_{v}}{\partial t}-D_{v} \frac{\partial^{2} p_{v}}{\partial z^{2}}=0
$$

Initially the partial pressure of the vapour is equal to the pressure imposed by the salt. The rapid displacement of the piston (time less than $5 \mathrm{~s}$ ) can be considered instantaneous with respect to 
the duration of the experiment which is of the order of $1000 \mathrm{~s}$ (Fig.2). Water vapour from the surface of the solution, progresses by diffusion into the gaseous phase.

The boundary conditions are:

- On the surface of the solution $z=0$ : flow $J_{v}$ deduced from (3) and diffusion law, gives the boundary condition in $z=0$ for $p_{v}$ :

$$
D_{v}\left(\frac{\partial p_{v}}{\partial z}\right)_{z=0}=-h_{g} \frac{\partial p_{g}}{\partial t}
$$

- On the surface of the piston $z=h_{g}$, the flux is zero, which according to Fick law results in:

$$
\frac{\partial p_{v}}{\partial z}=0
$$

The diffusion coefficient of water vapour in the air $D_{v}$ is given by the empirical relation [4]:

$$
D_{v}=0.217 \times 10^{-4}\left(\frac{P_{0}}{P_{g}}\right)\left(\frac{T}{T_{g}}\right)^{1.88} \text { in }\left(m^{2} s^{-1}\right)
$$

Equations (5) to (8) are used to calculate the partial vapour pressure profile using the finite differences method along an axis normal to the interface. These profiles are shown in Fig. 4 in the case of pure water.

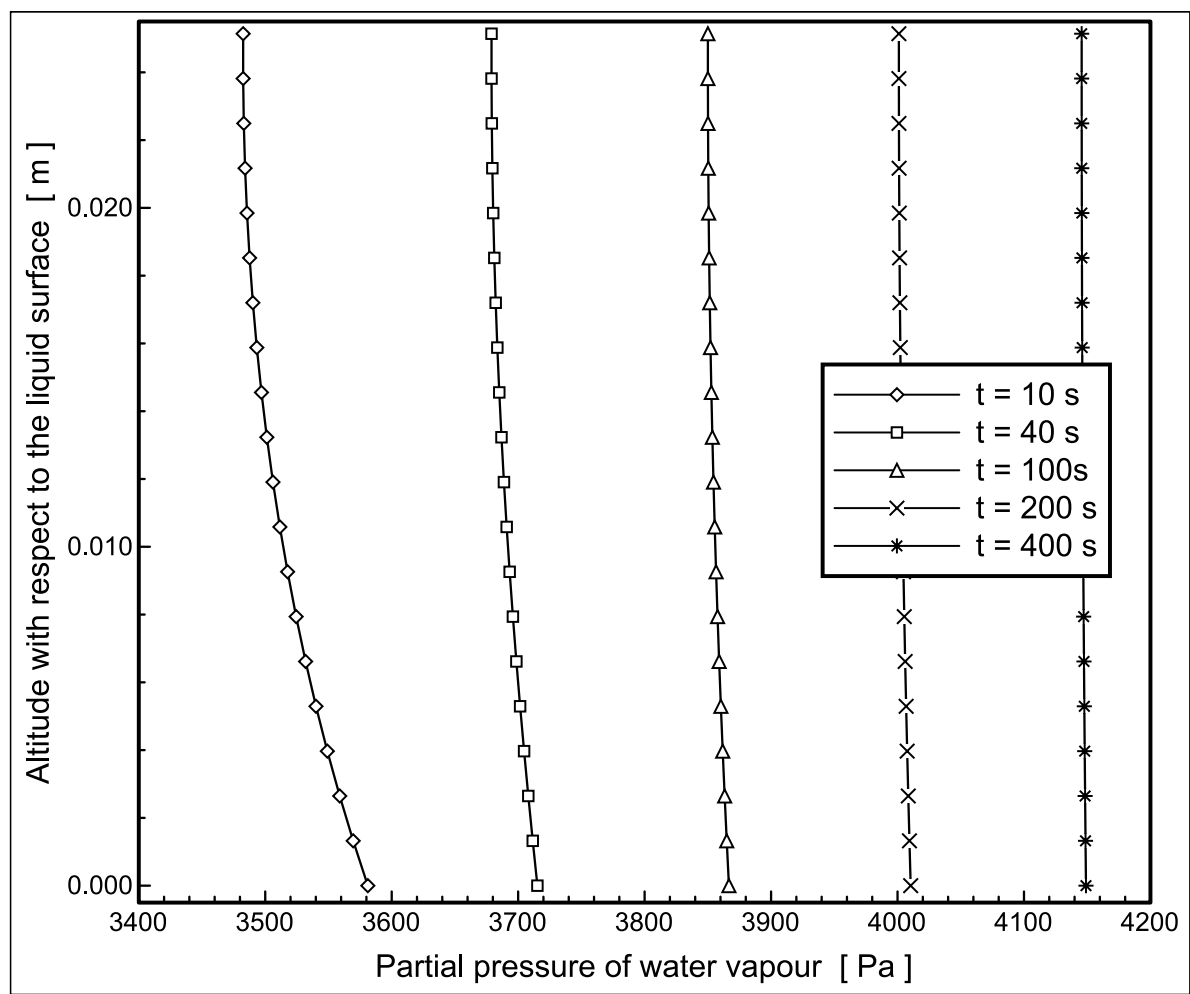

Figure 4: Vapour partial pressure profiles from numerical computation - Case of pure water 
After $40 \mathrm{~s}$ the difference in the partial pressure of vapour between the liquid surface and the lower face of the piston represents $1 \%$ of the partial pressure of vapour. Hypothesis $\mathrm{H} 4$ of a nearly uniform partial pressure profile was adopted. This implies that the partial pressure of the air is constant throughout the experiment; it is deduced from the values in the final state by (2).

\section{Macroscopic model of evaporation at the interface during experiments}

A macroscopic model of the interface can be deduced from the linear Thermodynamics of Irreversible Processes $[5,6,8,9,10]$. Development of mass, momentum, energy and entropy balance leads to expressing the production rate of entropy at the interface due to phase change. In the dissipation, the driving force of phase change appears to be the water chemical potential and temperature jumps across the interface. The linearization between flux and forces, in the neighbourhood of equilibrium leads to expressing the evaporation rate $J_{v}$ and energy flux $Q$, positively counted in the direction: solution $\rightarrow$ gas phase:

$$
\begin{aligned}
& J_{v}=\frac{L_{w w}^{S}}{T_{l}}\left(\mu_{w, T_{l}}-\mu_{v, T_{l}}\right)-L_{w q}^{S}\left(\frac{1}{T_{l}}-\frac{1}{T_{g}}\right) \\
& Q=L_{w q}^{S}\left(\mu_{w, T_{l}}-\mu_{v, T_{l}}\right)-L_{q q}^{S}\left(\frac{1}{T_{l}}-\frac{1}{T_{g}}\right)
\end{aligned}
$$

By using the global heat balance in the vicinity of the interface, it is shown [9] that the chemical potentials $\mu_{w, T_{l}}$ and $\mu_{v, T_{l}}$ are the chemical potentials evaluated at the temperature of the liquid phase $L_{w w}^{S}, L_{q q}^{S}, L_{w q}^{S}$ are the surface Onsager transfer coefficients. Since the TPI approach is macroscopic, it gives no information on the structure of the phenomenological coefficients; their knowledge is based on the experiments.

With the perfect gas hypothesis, the mass chemical potential of water vapour is [2]:

$$
\mu_{v, T_{l}}=\mu^{+}\left(T_{l}, p^{+}\right)+\frac{R T_{l}}{M} \ln p_{v}
$$

where $\mu^{+}$is a reference chemical potential at the temperature of the liquid phase: $T_{l}$ and at the reference pressure $p^{+}$here taken equal to $1 . M$ is the molar mass of water.

At vapour-liquid equilibrium, the partial pressure of vapour is $p_{v}^{e q}$. Equality of chemical potential of liquid and water vapour leads from 11:

$$
\mu_{w, T_{l}}=\mu^{+}\left(T_{l}, p^{+}\right)+\frac{R T_{l}}{M} \ln p_{v}^{e q}
$$

the relation (9) takes the form:

$$
J_{v}=-L_{w w}^{S} \frac{R}{M} \ln \frac{p_{v}}{p_{v}^{e q}}-L_{w q}^{S}\left(\frac{1}{T_{l}}-\frac{1}{T_{g}}\right)
$$


The value $p_{v}^{e q}$ differs from saturated vapour pressure at the same temperature because of the presence of solute in the solution or the effects of interfaces in the case of multiphase medium. The deviation of $p_{v}^{e q}$ from $p_{v s}$ can be expressed using the activity of water:

$$
a_{w}=\frac{p_{v}^{e q}}{p_{v s}\left(T_{l}\right)}
$$

With hypotheses $\mathrm{H} 1$ to $\mathrm{H} 5$ the liquid-gas system can be considered as the juxtaposition of two homogeneous systems with partial pressure of water as the state variable. In the context of these hypotheses, the evaporation law that will be used later is written

$$
J_{v}=-L^{S} \frac{R}{M} \ln \frac{p_{v}}{p_{v}^{e q}}
$$

The isothermal surface change coefficient is noted later $L^{S}$.

\section{4- Determination of the phase change coefficient in relation to water activity and pressure gas phase}

The following analysis aims to validate the relation (15) and to study the influence of water activity in the solution and the total pressure of the gas phase on the surface coefficient $L^{S}$.

The flux by unit surface as a function of time $J_{v}(t)$ is derived from Fig.2 using (3). To prevent unphysical changes of the derivative of $\frac{d p_{g}}{d t}$ due to fluctuations in experimental points, smoothing is carried out: the average of the experimental values at $n$ contiguous experimental points $(n=21)$ is calculated and assigned to the middle of the interval. By displacement of the interval of $n$ points, a smoothed experimental curve is generated. Fig. 5 shows the variation of smoothed $\frac{d p_{g}}{d t}(t)$ over a pure water, a solution of $\mathrm{K}_{2} \mathrm{SO}_{4}$ and a solution of $\mathrm{MgNO}_{2}$ for various pressures. These points are approximated by polynomial, logarithmic or exponential functions to give analytical expressions of $\frac{d}{d t} p_{g}$ at the interface. 


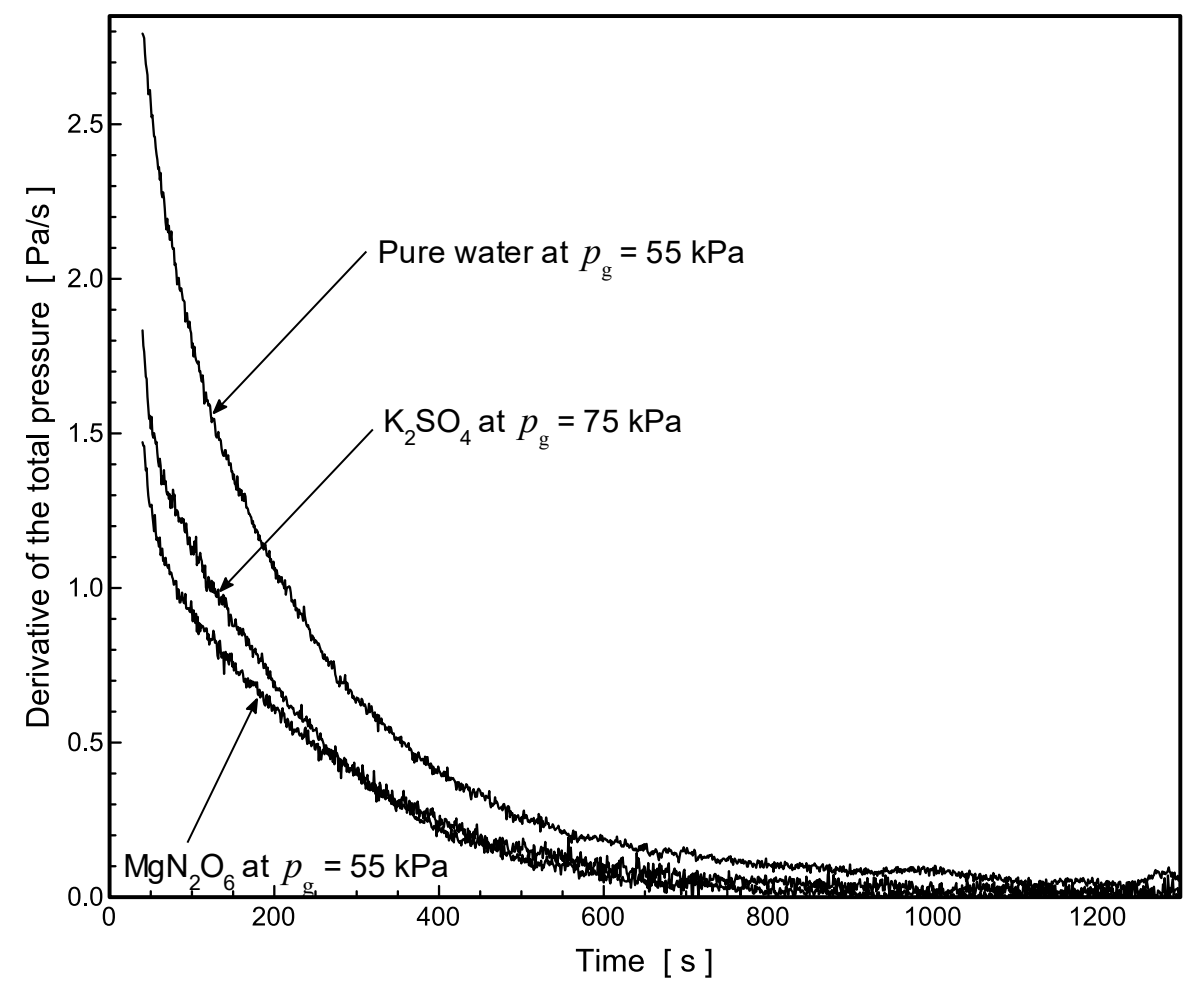

Figure 5: Examples of the evolution of smoothed derivative of total gas pressure

The partial pressure of vapour $p_{v}$ in (15) is deduced by (2), at all time, using assumption $H 5$ of constant partial pressure of air. Fig. 6 shows the variation of partial pressure of the vapour at the interface for 55,75 and $95 \mathrm{kPa}$, in the case of a solution of $\mathrm{KCl}\left(a_{w}=0.85\right)$. 


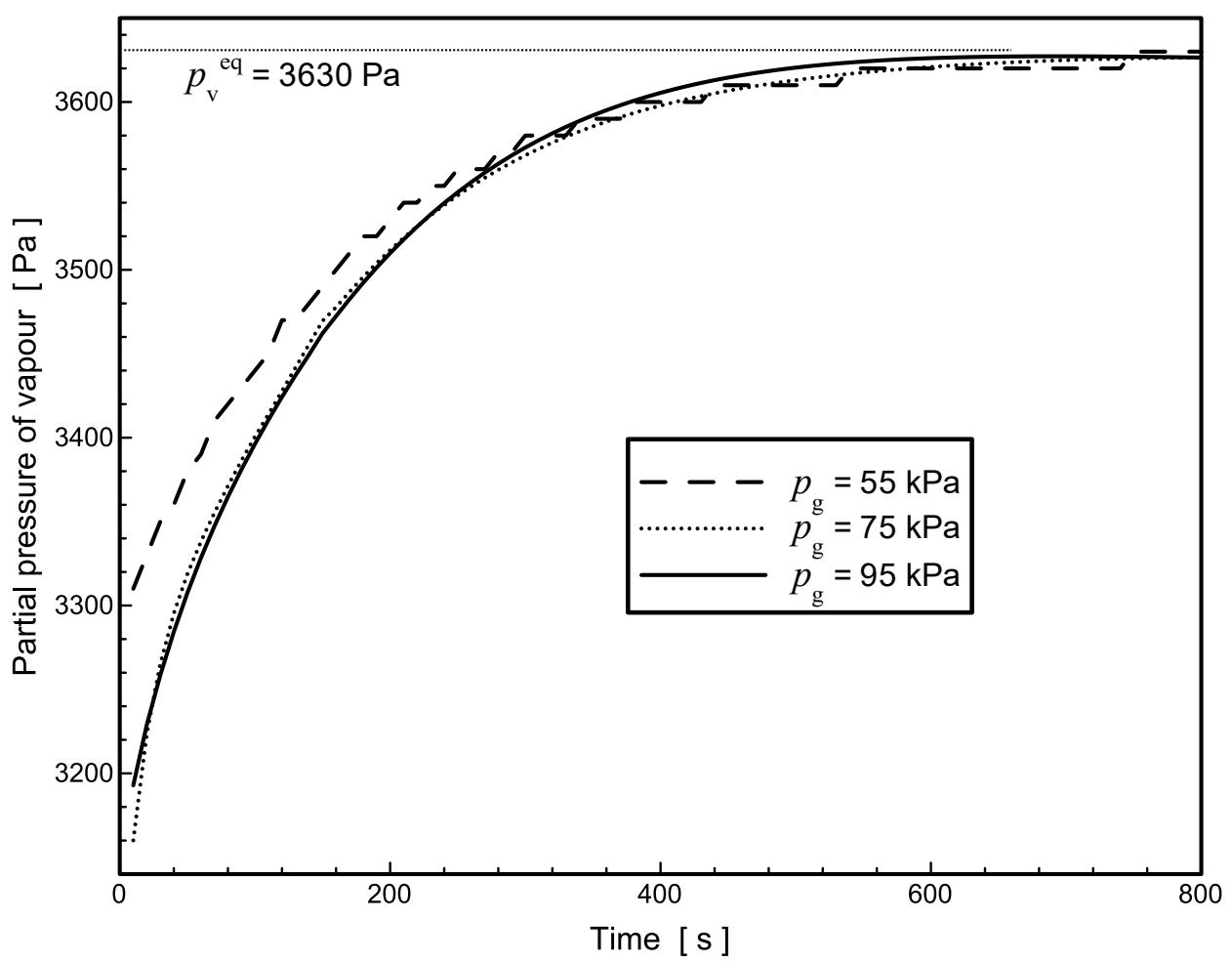

Figure 6: Evolution of vapour partial pressure at the surface of a $\mathrm{KCl}$ solution for different total gas pressure

Knowing $\frac{d}{d t} p_{g}$ and $p_{v}$ at any time, it is possible to trace the flux as a function of the thermodynamic force at the interface $\frac{R}{M} \ln \frac{p_{v}}{p_{v}^{e q}}(15)$. The flux-force relationship is shown in Fig.7 for pure water and Fig.8 for a solution of $\mathrm{MgNO}_{2} \mathrm{O}_{6}\left(a_{w}=0.23\right)$ and for the three pressures.

Generally, the flux-force relation relative to a dissipative phenomenon reveals a linear domain near-equilibrium, and a non-linear domain far from equilibrium (Fig.7) [12, 13]. This is particularly the case for chemical reactions [10] and phase change phenomena in soils $[6,14$, 15], which are particular chemical reactions

The coefficient $L^{S}$ is deduced from the slopes of the linear parts for the imposed activities and pressures. The value of $L^{S}$ are shown in Fig.9, in relation to the water activity, for the three pressures. The values of the coefficients $L^{S}$ are also reported in Tab.4.

It is found that at constant pressure, the coefficient $L^{S}$ decreases with the activity and. For a given activity, this coefficient increases with the pressure of the gas phase. 


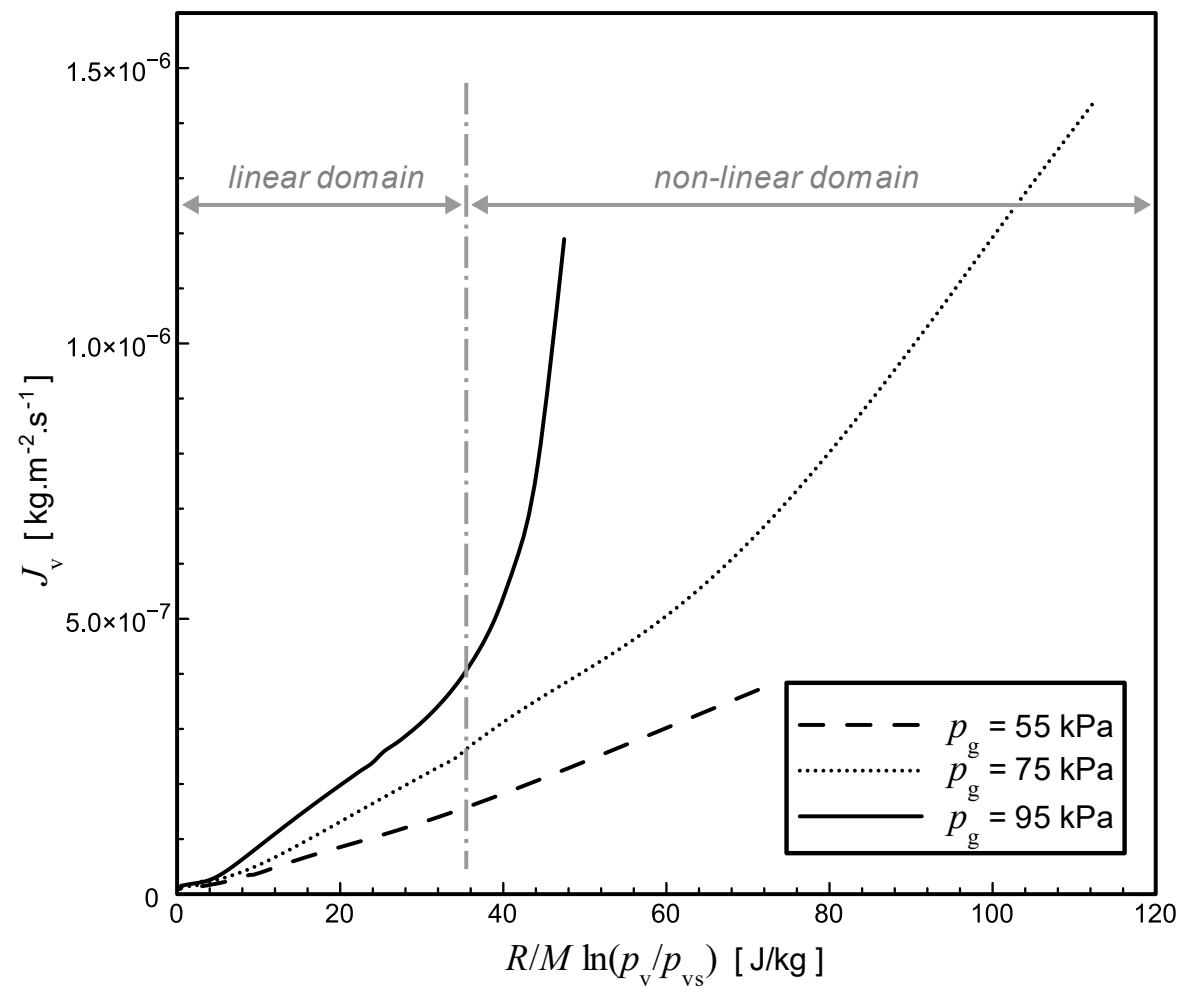

Figure 7: Variation of isothermal surface flux as a function of the thermodynamic force for different total gas pressure - Case of pure water

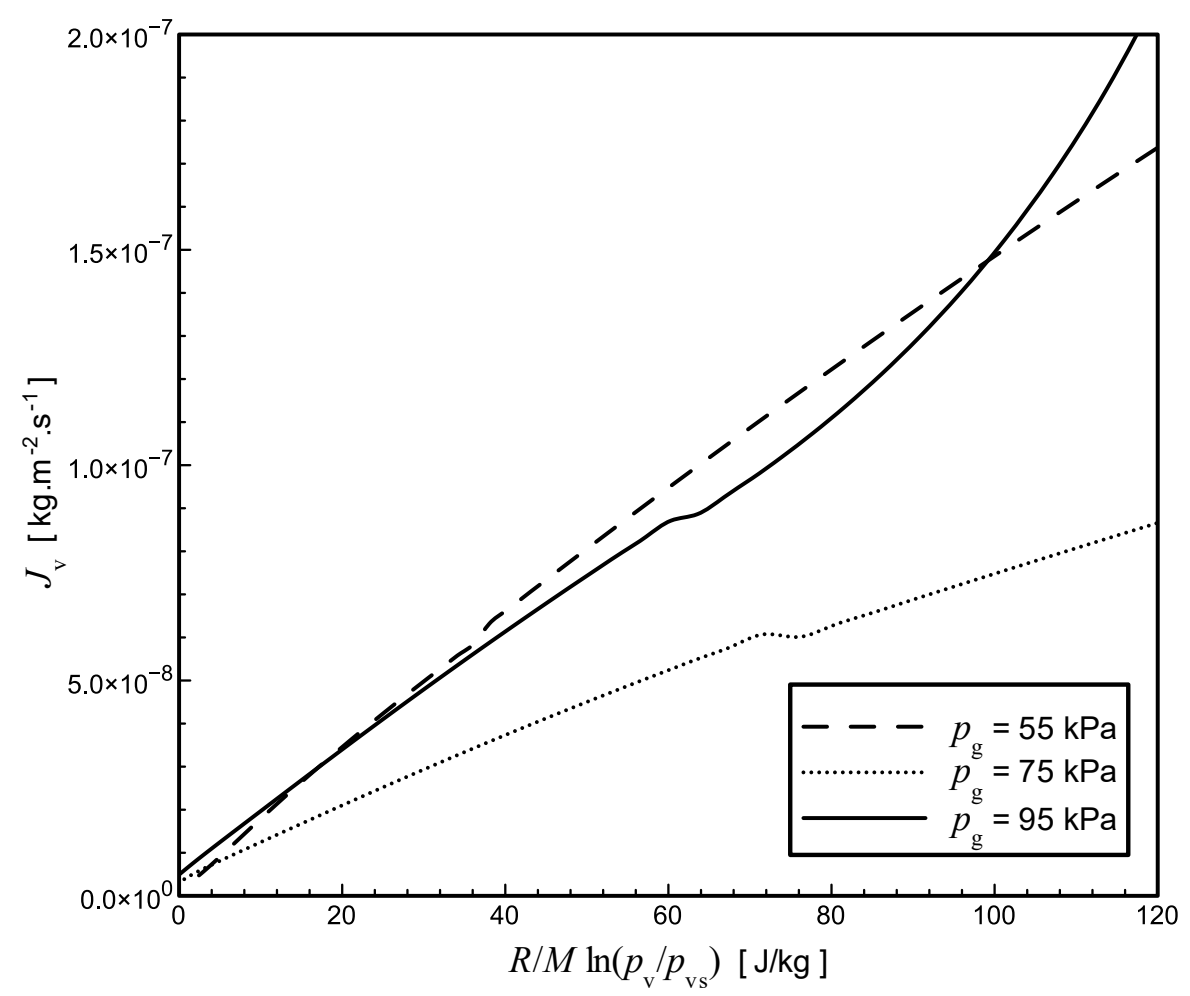

Figure 8: Variation of isothermal surface flux as a function of the thermodynamic force for different total gas pressure - Case of $\mathrm{MgN} 206\left(a_{w}=0.23\right)$ 
Figures 7 and 8 provide information on the extent of the linearity domain. It is observed in these figures, as is the case for the other experimental conditions, that the linearity range decreases as the vaporization rate increases.

Table 4: Value of the isothermal phase change coefficient $L^{S}$ versus water activity for different gas pressure

\begin{tabular}{cccc}
\hline Water activity $(/)$ & $\boldsymbol{P}_{\boldsymbol{g}}=\mathbf{5 5} \mathbf{~ k P a}$ & $\boldsymbol{P}_{\boldsymbol{g}}=\mathbf{7 5} \mathbf{~ k P a}$ & $\boldsymbol{P}_{\boldsymbol{g}}=\mathbf{9 5} \mathbf{~ k P a}$ \\
\hline 0.12 & $1.76 \times 10^{-10}$ & $1.06 \times 10^{-9}$ & $1.23 \times 10^{-9}$ \\
\hline 0.23 & $7.06 \times 10^{-10}$ & $1.32 \times 10^{-9}$ & $1.59 \times 10^{-9}$ \\
\hline 0.55 & $1.59 \times 10^{-9}$ & $4.23 \times 10^{-9}$ & $4.59 \times 10^{-9}$ \\
\hline 0.66 & $2.38 \times 10^{-9}$ & $5.12 \times 10^{-9}$ & $5.47 \times 10^{-9}$ \\
\hline 0.75 & $3.26 \times 10^{-9}$ & & $7.76 \times 10^{-9}$ \\
\hline 0.85 & $4.23 \times 10^{-9}$ & $7.39 \times 10^{-9}$ & $8.47 \times 10^{-9}$ \\
\hline 0.97 & $4.59 \times 10^{-9}$ & $7.41 \times 10^{-9}$ & \\
\hline 1.00 & $5.29 \times 10^{-9}$ & $8.64 \times 10^{-9}$ & $1.15 \times 10^{-8}$ \\
\hline
\end{tabular}

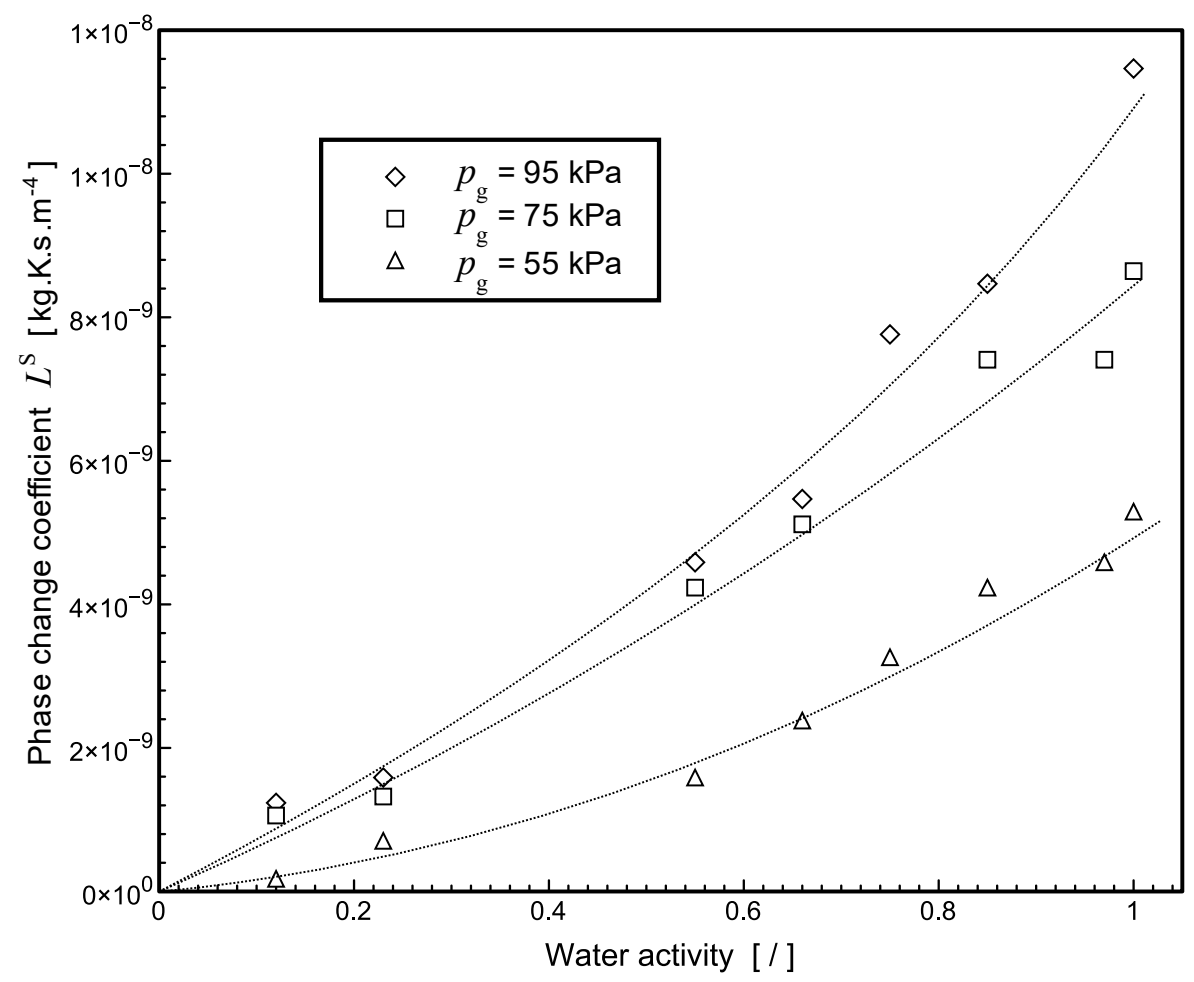

Figure 9: Variation of the isothermal surface phase change coefficient LS as a function of water activity for different total gas pressure 
By definition, the mass chemical potential of water represents the variation of internal energy of the liquid phase when a unit mass of water is extracted. It reports on the binding energy of water with its environment. When activity, of liquid water tends to zero, the chemical potential of water (12) approaches $-\infty$; this implies the need to apply a large amount of energy to remove molecules of water. The high value of the water binding in the solution makes the phenomena of evaporation very slow; the phase change coefficient approaches zero. When $a_{w}$ increases, the binding of water molecules decreases and the efficiency of the phenomena of evaporation increases. This results in an increase of the coefficient $L^{S}$ when water activity increases.

The effect of total pressure of the gas phase can be explained using a molecular description [8, 16]. For these authors three mechanisms are involved in the phase change process (Fig.10): evaporation and condensation of a water molecule, expulsion of a water molecule by a molecule of the gas phase (molecular exchange).

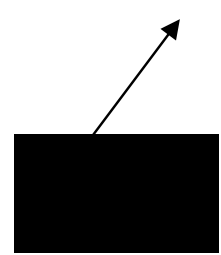

Evaporation

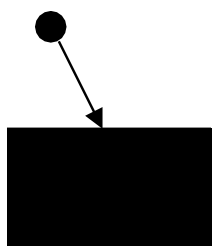

Condensation

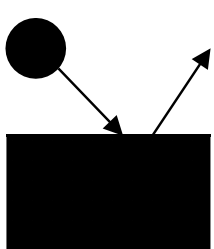

Molecular exchange

Figure 10: Different evaporation mechanisms of a molecule of water [16]

In the experiments, the gas phase was mainly composed of air; the ratio between vapour pressure of water and air was of the order of a few percent. When the air pressure decreased the number of collisions between air molecules and molecules constituting the interface also decreased, evaporation by molecular exchange was attenuated resulting in a decrease of coefficient $L^{S}$.

\section{Global validation experiment}

Analysis of the experimental results is dependent on the hypotheses proposed and discussed in section 3. Although these are well verified numerically, an experimental study is not immune to a parasitic phenomenon. For this reason, a global experimental verification study is proposed. His goal is to verify if the relation (15) and the coefficient $L^{S}$ are able to predict the evolution of pressure during an experiment totally different from those at the origin of their study. During the validation experiment, the dimensions of the measuring chamber, the method for measuring the partial vapour pressure, and the method for lowering the partial vapour pressure at the initial state were modified. 


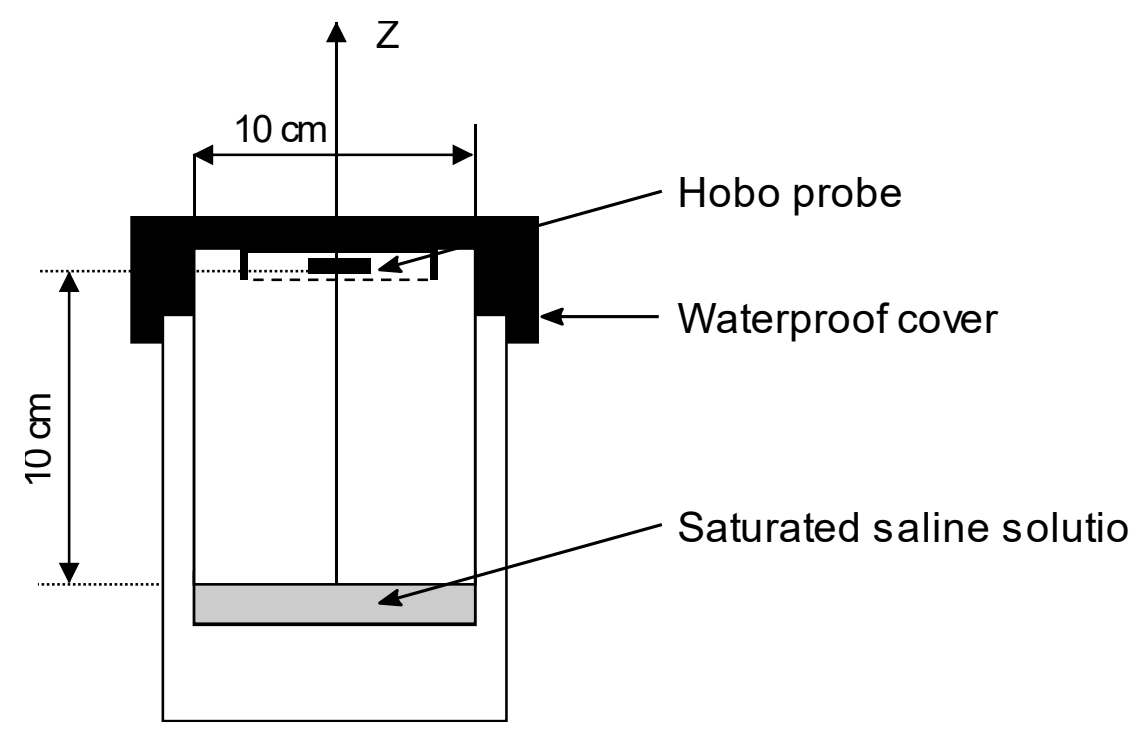

Figure 11: Schema of the experimental device used for validation

Experimental verification was performed on a device shown in Fig.11. This device consisted of a cylindrical sealed enclosure of $10 \mathrm{~cm}$ in diameter and $10 \mathrm{~cm}$ high. At its base a saturated saline solution was introduced, at the top a Hobo sensor was placed which directly gave the relative humidity of the air by measuring the capacity of a capacitive element absorbing moisture. The manufacturer gave accuracy of 5\% in the measuring range, between $25 \%$ and $90 \%$. On the other hand, the balance between the sensing element and the surrounding atmosphere was not immediate, introducing a delay in measurement.

The processing of an experiment includes the following steps:

1/ At the initial time, the saline solution is placed in the mould. The height of the part occupied by the air is measured.

$2 /$ Ventilation occurred on the surface, resulting in a change in the relative humidity of the gas phase to reach ambient humidity (of the order of 50\%). This technique only works for saline solutions that fix water activity above $50 \%: \mathrm{NaCl}\left(a_{w}=0.75\right)$ and $\mathrm{NaNO}_{2}\left(a_{w}=0.66\right)$.

3/ The mould is then sealed; recording of the relative humidity by the Hobo sensor begins. For the reasons just mentioned, the experiment is reliable only for two salts. Experimental evolutions are shown in Fig.12.

4/ The theoretical model used differs from the model presented in H5 by the boundary condition at the interface; the flux is calculated by (15) with the coefficients of Fig.9; thus, all the results of the study are used. The model gives the evolution of the relative humidity of the air Fig.12. For $\mathrm{NaCl}$, this figure highlights the slowness of the sensor to reach the value of 0.75 imposed by the salt. 
$5 /$ The evolution of air humidity given by the sensor is compared to the theoretical evolution (Fig.12). In spite of a divergence, largely imputed to the capacitive sensor, there is a general similarity of the curves and a similar equilibrium return time.

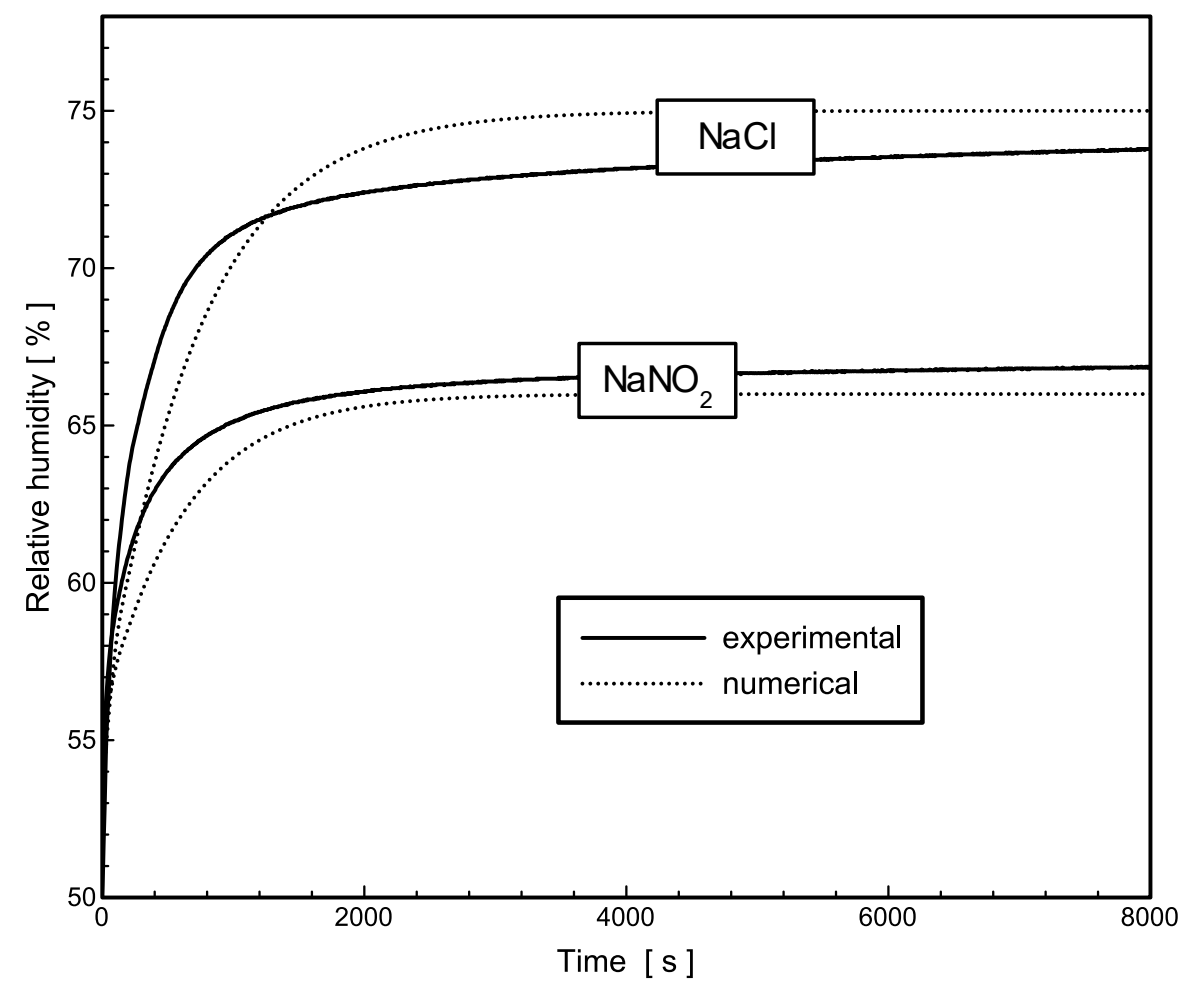

Figure 12: Comparison between the evolutions of relative humidity obtained from numerical computation and measured by a capacitive sensor for 2 different salt solutions

\section{Conclusion}

The experimental device isolates the phase change under the action of a chemical potential discontinuity. It provides further insight compared to experiments introducing a heat input [4] or a renewal of vapour at the interface [1]. Vaporization is produced by a sufficiently fast mechanical energy supply to be assumed to be an impulse allowing to categorize this method as a transient method. The advantages are the short duration of the measurement and the low impact on the global physical parameters, like temperature or liquid activity. The recording of the total gas pressure makes it possible to analyse the return to equilibrium and measure the phase change rate. In the proposed study, the phase change generated by the discontinuity of the water chemical potential is the predominant phenomenon. The hypotheses used to exploit the experiment were validated numerically from the experimental results. Additionally, a global validation experiment confirms all the hypotheses. The short duration of experiments makes it possible to analyse the influence of various parameters, such as the temperature, the gas pressure and the liquid activity. 
The decrease in phase change coefficient $L^{S}$ with activity reveals an increase in the retention of water molecules by the solution. The increase in $L^{S}$ with the pressure reveals an increase in the molecular exchanges which is predominant. A finer analysis of the $L^{S}$ coefficient is meaningless with the macroscopic approach used here, only a microscopic analysis would go further. Given the precautions taken to minimize any phenomena other than the discontinuity of the chemical potential, the experimental results should be used as an experimental basis for validating microscopic models.

In complex tri-phasic media: soils, food products, biological tissues ..., the activity of water is modified by liquid-gas and liquid-solid interfaces. For instance, the relationship between water content and activity is accurately given by the desorption isotherm. The evaporation at the surface of these media is translated by a relationship similar to $(15)[5,6]$. The experimental technique presented here was used in the case of trichloroethylene [17] to analyse the phase change behaviour at the surface of a soil. An experiment different from the one presented here, has shown that the law (15) is verified [6]. The exploitation of these experiments confirms that the vaporization rate increases with the water activity and the total gas pressure.

\section{Acknowledgments}

This research was supported by the University of Montpellier, the Centre National de la Recherche Scientifique (France), the Joseph Ki-Zerbo University, Ouagadougou and the Nazi Boni University, Bobo Dioulasso (Burkina-Faso).

Pr. Jean-Claude Bénet deceased on July $27^{\text {th }} 2019$ while he was finishing this manuscript. This publication is an homage to its extensive contribution on this subject.

\section{References}

[1] G. Fang, C.A. Ward, Temperature measured close to the interface of an evaporating liquid, Physical Review 59 (1999) 417-428.

[2] E.Y. Gatapova, I. Graur, O.A. Kabov, V.A. Aniskin, M.A. Filipenko, F. Sharipov, The temperature jump at water-air interface during evaporation, International Journal of Heat and Mass Transfer 104 (2017) 800-812.

[3] M. A. Kazemi, D. S. Nobes, and J. A. W. Elliott, Experimental and Numerical Study of the Evaporation of Water at Low Pressures, Langmuir 33 (2017) 4578-4591.

[4] V.K. Badam, V. Kumar F. Durst, K. Danov, Experimental and theoretical investigations on interfacial temperature jumps during evaporation, Experimental Thermal and Fluid Science 32 (2007) 276-292.

[5] J.-C. Bénet, P. Jouanna, Non equilibre thermodynamique dans les milieux poreux non saturés avec changement de phase, International Journal of Heat and Mass Transfer 26 (1983) 1585-1595. 
[6] J.-C. Bénet, A.-L. Lozano, F. Cherblanc, B. Cousin, Phase Change of Water in a Hygroscopic Porous Medium - Phenomenological Relation and Experimental Analysis for Soil Water, Journal of Non-Equilibrium Thermodynamics 34 (2009) 133-153.

[7] S. Ouoba, F. Cherblanc, B. Cousin, J.-C. Bénet, A new experimental method to determine the sorption isotherm of a Liquid in a porous medium, Environmental Science \& Technology 44 (2010) 5914-5919.

[8] D.A. De Vries, A.J. Kruger, On the value of the diffusion coefficient of water vapour in air, Colloque international du CNRS n ${ }^{\circ} 60$, Paris 18-20 avril 1966, Editions du CNRS (1967) 6172 .

[9] D. Bedeaux, S. Kjelstrup, Transfer coefficients for evaporation, Physica A 270 (1999) 413426.

[10] D. Bedeaux, S. Kjelstrup, Irreversible thermodynamics - a tool to describe phase transitions far from global equilibrium, Chemical Engineering Science 59 (2004) 109-118.

[11] E.A. Guggenheim, Thermodynamique, Dunod, Paris (1965).

[12] I. Prigogine, D. Kondepudi, Thermodynamique, Odile Jacob, Paris (1999).

[13] C. Vidal, G. Dewel, P. Borckmans, Au-delà de l'équilibre, Hermann Paris, 1993.

[14] A.-L. Lozano, F. Cherblanc, B. Cousin, J.-C. Bénet, Experimental study and modelling of the water phase change kinetics in soils, European Journal of Soil Science 59 (2008) 939-949.

[15] A.-L. Lozano, F. Cherblanc, J.-C. Bénet, Water Evaporation Versus Condensation in a hygroscopic soil, Transport in Porous Media 80 (2009) 209-222.

[16] M. Matsumoto, Molecular dynamics of fluid phase change, Fluid Phase Equilibria 144 (1998) 307-314.

[17] S. Ouoba, T. Daho, F. Cherblanc, J. Koulidiati, J-C. Bénet, A new experimental method to determine the evaporation coefficient of trichloroethylene (TCE) in an arid soil, Transport in Porous Media 106 (2015) 339-353. 